\title{
Differenz
}

Revista internacional de estudios heideggerianos y sus derivas contemporáneas

AÑO 3 NÚMERO 2: JULIO DE 2016. E-ISSN: 2386-4877 - DOI: 10.12795/Differenz.2016.i02.03

[pp. 47-62]

Recibido: $21 / 04 / 2016$

Aceptado: 14/06/2016

\section{El método fenomenológico en los Seminarios de Zollikon de Martin Heidegger}

\section{The phenomenological method in Zollikon Seminars by Martin Heidegger}

Noé Expósito Ropero

Universidad Nacional de Educación a Distancia (UNED)

Resumen:

En este trabajo, centrado en los Seminarios de Zollikon de Martin Heidegger, abordo la ambigua y compleja relación entre Heidegger, Husserl y la fenomenología, mediada por la problemática del método fenomenológico. La tesis que pretendo mostrar es que, a pesar de la postura explícita de Heidegger, en la que se muestra crítico con su maestro, Heidegger estaría asumiendo, implícitamente, tanto el método como la fenomenología de Husserl, la cual es puesta en práctica en estos Seminarios. Para mostrar esta tesis, analizo dos nociones fundamentales de la fenomenología de Husserl, en las que Heidegger basa toda su argumentación: cuerpo (Körper) y cuerpo vivido (Leib).

Palabras Clave: Heidegger; Husserl; método fenomenológico; cuerpo (Körper); cuerpo vivido (Leib). 


\section{Abstract:}

In the present paper, focused on the Zollikon Seminars by Martin Heidegger, I will explain the ambiguous and complex relationship among Heidegger, Husserl, and the phenomenology, through the analysis of phenomenological method. The idea that I want to show is that, despite the explicit attitude of Heidegger, which shows his differences with his master, Heidegger seems to be assuming, implicitly, both the method and Husserl's phenomenology. This is evidenced in the aforementioned text. In order to support this thesis, I analyze two fundamental ideas of Husserl's phenomenology, on which Heidegger based all his arguments: Body (Körper) and lived body (Leib).

Keywords: Heidegger; Husserl; phenomenological method; physical body (Körper); lived body (Leib).

\section{Introducción}

Son conocidas las palabras de Nietzsche según las cuales «es necesario, resulta deseable que el filósofo se convierta en una planta rara», ya que, frente a Séneca o Cicerón, para Nietzsche, "la filosofía no tiene que ver nada con la virtud", del mismo modo que "el hombre científico no tiene nada que ver con el filósofo» ${ }^{1}$. Estas palabras de Nietzsche, según me parece, han calado profundamente en el imaginario colectivo contemporáneo, pues, ciertamente, así suele ser percibido el filósofo, tanto en el ámbito social como en el académico: alguien que se ocupa de todo y de nada. Sin embargo, esta imagen del filósofo y su función encierra un gran peligro, pues basta recurrir a ella para excluir a la filosofía de cualquier problemática seria, siendo un tópico asumido que la filosofía, a diferencia de la ciencia, carece de un método riguroso desde el cual pueda responder a las exigencias de la vida cotidiana, aquéllas que en realidad nos preocupan y nos afectan. Por ello, la organización de estas «ll Jornadas Differenz: Heidegger y la psiquiatría » nos ofrece una magnífica oportunidad para establecer un diálogo crítico e interdisciplinar, en este caso, entre la filosofía y la psiquiatría.

1. NIETZSCHE, F.: La voluntad de poderío, EDAF, Madrid, 1981.Traducción de Aníbal Froufe, p. 240.

2. Quiero agradecer muy sinceramente a los organizadores de estas Jornadas el amistoso y entrañable trato recibido, así como su inestimable esfuerzo durante todas las Jornadas por propiciar un inmejorable ambiente de trabajo, diálogo y pensamiento. Durante estas Jornadas en Sevilla surgieron amistades, propuestas de trabajo en común e ideas que, seguro, darán lugar a futuros encuentros y colaboraciones. 
En este contexto, y tomando como hilo conductor los Seminarios de Zollikon ${ }^{3}$ de Martin Heidegger, el objetivo de este trabajo será mostrar el decisivo papel que el método fenomenológico de Edmund Husserl ${ }^{4}$ juega en los planteamientos de Heidegger, método que recorre toda su trayectoria filosófica, y que en estos Seminarios no es sólo revindicado teóricamente, sino puesto en práctica para articular una respuesta alternativa y rigurosa a la visión cientificista del ser humano. De este modo, ha de advertirse desde el comienzo, que Heidegger no está combatiendo «la ciencia en cuanto ciencia, sino sólo la absolutización de la ciencia natural», pues lo que está en juego, afirma, no es una cuestión meramente teórica, sino «la destrucción del ser humano» $(2013,197)$.

Esta problemática recorre los Seminarios de principio a fin, de ahí que Heidegger se empeñe en retrotraer la discusión con los psiquiatras a dos puntos decisivos, a saber: en primer lugar, a la cuestión del método y, en segundo lugar, a la concepción del ser humano que subyace a las ciencias naturales, resultando que, en última instancia, ambas cuestiones quedan intrínsecamente relacionadas. Sin embargo, para Heidegger, el problema del método será el fundamental, dado que éste fundamenta, justifica e instaura una determinada concepción del ser humano. El método, en definitiva, implica ya una pre-comprensión de la realidad, de ahí que con la discusión metodológica se apunte, a su vez, a una doble problemática: en primer lugar, pretende Heidegger denunciar los prejuicios metodológicos y ontológicos que subyacen al método de las ciencias naturales, resultando ésta una tarea negativa o deconstructiva -en consonancia con la conocida «Destruktion» planteada en Ser y tiempo ${ }^{5}$. Pero esta primera tarea sólo cobra pleno sentido en función de la segunda, ya positiva o constructiva, cuyo objetivo sería ofrecer una alternativa tanto metodológica como ontológica a las ciencias naturales, para cuya articulación recurre Heidegger a la fenomenología y su método.

Por tanto, y este es el tema central que aquí nos ocupa, cuando Heidegger reivindica el método fenomenológico, no se está apelando únicamente a un método, sino a una concepción del ser humano y su realidad. Ciertamente, Heidegger insiste en la cuestión del método, pero la importancia de éste reside, en última instancia, en la posibilidad de

3. Heidegger, M.: Seminarios de Zollikon, México, Herder, 2013. Traducción de Ángel Xolocotzi Yáñez. En lo que sigue incluiré las citas en el cuerpo textual para agilizar la lectura y la exposición.

4. Para una exposición detallada y sistemática del método fenomenológico de Husserl cfr. SAN MARTín, J.: La estructura del método fenomenológico, UNED, Madrid, 1986. Me permito remitir al lector a mi extensa reseña de la obra citada: "La estructura del método fenomenológico de Javier San Martín", en Reflexiones Marginales, Año 5, Número 29, octubre-noviembre 2015, sobre Fenomenología: http://reflexionesmarginales.com/3.0/javier-san-martin-la-estructura-delmetodo-fenomenologico/

5. HeIDEGGER, M. (1927): El ser y el tiempo, FCE, México, 2007. Traducción de J. Gaos., p. 30 y ss. 
hacer justicia a la realidad tal y como ésta se nos presenta, es decir, en la posibilidad de mostrarnos la realidad más allá de los prejuicios metodológicos que la transfiguran. Esto no significa que la fenomenología pretenda algo así como un acceso privilegiado a la realidad en sí -según la distinción kantiana-, sino que se asume una realidad fenoménica que se configura y se nos muestra siempre en perspectivas. Ahora bien, no por ello debemos caer en el error de aceptar que todas las perspectivas sean igualmente valiosas o que todas hagan justicia al objeto o ámbito investigado. En torno a esta problemática girará toda la discusión de Husserl y Heidegger con la metodología científica y su comprensión del ser humano. Éstas últimas no son falsas, pero, para Heidegger, deben retrotraerse a una más originaria y fundamental: «la mirada fenomenológica sigue siendo una o, incluso, la contribución fundamental» $(2013,131)$.

Por tanto, el trasfondo de la problemática metodológica es ontológico, de ahí la rotunda afirmación de Heidegger en Ser y tiempo, plenamente vigente en estos Seminarios: «la ontología sólo es posible como fenomenología», de modo que

ontología y fenomenología no son dos distintas disciplinas pertenecientes con otras a la filosofía. Estos dos nombres caracterizan a la filosofía misma por su objeto y por su método6.

Nos encontramos, así, en el círculo hermenéutico propio de la existencia humana, pero Heidegger no sucumbirá -como tampoco Husserl-ante la multiplicidad e infinitud de interpretaciones posibles de la realidad, sino que ambos reivindicarán la fenomenología como punto de partida fundamental para articular una imagen alternativa del ser humano o Dasein. Esta tarea filosófica resulta, por lo demás, de plena actualidad, pues también hoy -amén de las neurociencias- se pretende instaurar una explicación total del ser humano en términos cientificistas. Esta es, precisamente, la problemática central que Heidegger aborda en estos Seminarios.

Sin embargo, podría objetarse contra Husserl, Heidegger y la fenomenología que no existe algo así como «el» método científico, sino que cada ciencia posee un método propio y técnicas particulares. Desde esta perspectiva, poco o nada tendría que ver la técnica del físico cuántico con la del biólogo, por ejemplo. Esta protesta del científico está justificada, pero, a ojos del fenomenólogo, tanto el físico como el biólogo compartirían una determinada aproximación a la realidad, esto es, una determinada pre-comprensión de la misma que los orienta hacia un determinado dominio de la realidad, ocultándose lo más propio y fundamental de la misma. El argumento central de la fenomenología será, tal y como lo expresa Heidegger, que toda aproximación y comprensión de la realidad -entre

6. Ibídem, pp. 46-49. 
ellas la científica- sólo es posible gracias al «rasgo fundamental del ser-humano», cifrado en su «carácter de abierto para lo presente» $(2013,127)$. Ahora bien, este carácter de abierto para lo presente no puede entenderse como algo abstracto, psicológico o mero presupuesto teórico, sino que éste remite a la distinción fenomenológica fundamental entre ser humano como "cuerpo vivido» o "soma» (Leib) y ser humano como mero "cuerpo» cósico (Körper) ${ }^{7}$. Esta distinción de Husserl, establecida ya, como veremos, en torno a 1910-1912, y desarrollada definitivamente en Ideas ${ }^{8}{ }^{8}$, será la que Heidegger adopte como hilo conductor en su discusión con los psiquiatras, mostrándoles que, en última instancia, el método científico de las ciencias naturales toma al ser humano como mero «cuerpo» (K) y no como «cuerpo vivido» o "viviente» (L), quedando así la noción de ser humano reducida a lo meramente cósico, medible, extenso.

Nuestro objetivo en lo que sigue será mostrar el trasfondo e implicaciones de estas problemáticas, con la doble finalidad de, por un lado, poner de relieve la importancia de la fenomenología de Husserl en los planteamientos de Heidegger y, por otro, reivindicar el potencial de la fenomenología y el papel decisivo que, a nuestro juicio, puede jugar en los debates filosóficos, científicos y socio-políticos actuales, y más aún cuando se trate de dar voz a la filosofía y su función frente a otras disciplinas o saberes.

\section{El método fenomenológico en los Seminarios de Zollikon.}

Al hilo de las cuestiones anteriormente suscitadas, y puesto de relieve el papel central que en ellas juega el problema del método, nos centraremos ahora en la siguiente pregunta: ¿en qué consiste el método fenomenológico?

Hemos señalado que Heidegger se rebela contra «la absolutización de la ciencia natural» y su metodología, pero esta "Destruktion» o deconstrucción no nos ofrece por sí misma la articulación de un método alternativo -el fenomenológico. Suelen insistir los interpretes de Heidegger en que no hay algo así como un método en su filosofía, de ahí que -se afirma- «hablar de cuestiones metodológicas en la obra de Heidegger resulta un tanto artificioso» (R. Rodríguez, 1994, 72 y ss.). Sin embargo, Heidegger nunca dejó de reivindicar el método fenomenológico, ya desde Ser y tiempo, hasta los Seminarios

7. En lo que sigue, adoptando la propuesta de Ángel Xolocotzi en su traducción, abreviaré el término «Körper» con "K» y «Leib» con "L». Como veremos, esta distinción resultará fundamental en la fenomenología de Husserl y Heidegger, y en torno a ella girará toda la discusión con las ciencias naturales.

8. HUSSERL, E.: Ideas relativas a una fenomenología pura y una filosofía fenomenológica. Libro Segundo: Investigaciones fenomenológicas sobre la constitución, México, FCE, 1997. Traducción de A. Zirión. 
que nos ocupan. Es cierto que Heidegger no ofrece en estos Seminarios una exposición sistemática de cuáles sean las nociones fundamentales del método reivindicado, sino que, como sucede en la Introducción de $\operatorname{Ser}$ y tiempo $^{9}$, sólo encontramos aquí algunas indicaciones formales y una serie de afirmaciones que, por lo demás, poco pueden ayudarnos a establecer rigurosamente qué fenomenología reivindica Heidegger. Esta dificultad se agrava si tenemos en cuenta que los interlocutores de Heidegger no son estrictamente filósofos, de ahí que resulte muy poco probable que los psiquiatras allí presentes se forjasen una mínima idea de qué era la fenomenología y su método atendiendo exclusivamente a las sentencias - a veces un tanto crípticas- que Heidegger enuncia. Es obvio que la estrategia de Heidegger consiste aquí en mostrar y poner en práctica el método fenomenológico, más que en explicarlo o sistematizarlo teóricamente, pero, en cualquier caso, según me parece, supondría un grave error pensar que no hay método alguno detrás de esta práctica fenomenológica. Baste recordar que el propio Heidegger abordó expresamente esta problemática en Conceptos fundamentales de la fenomenología (1927), donde afirma que

Estos tres componentes fundamentales del método fenomenológico, reducción, construcción y destrucción, se pertenecen mutuamente y deben ser fundamentados en su pertenencia mutua ${ }^{10}$.

Lo que nos planteamos aquí, por tanto, no es si Heidegger asume el método fenomenológico o no -lo cual parece poco discutible-, sino a qué se refiere con dicho método y si éste difiere, como pretende Heidegger, del método fenomenológico de Husserl.

No debemos olvidar que, desde sus comienzos, Heidegger pretende distanciarse de su maestro, tornándose esta distancia irreversible a partir de los cursos que Heidegger imparte en Marburgo durante los años veinte, especialmente a partir de las críticas contra Husserl desarrolladas en Prolegómenos para una historia del concepto de tiempo ${ }^{11}$. Desde entonces, las críticas a la fenomenología de Husserl serán ya constantes y reiteradas. Es por ello que la situación se torna aquí compleja y ambigua: por un lado, Heidegger reivindica la fenomenología y su método, desde una perspectiva meramente formal, pero, por otro lado, critica insistentemente la fenomenología de Husserl, de modo que no sabemos muy bien a qué se refiere Heidegger. Esta ambigua relación ha desorientado tanto a

9. Ibídem, especialmente pp. 37-49.

10. HEIDEGGER, M.: Conceptos fundamentales de la fenomenología, Trotta, Madrid, 2000. Traducción de J. J. García Norro, p. 48.

11. HeIdegGeR, M.: Prolegómenos para una historia del concepto de tiempo, Alianza, Madrid, 2006. Traducción de J. Aspiunza Elguezabal, cfr. pp.142 y ss. 
discípulos directos de Heidegger como a gran parte de sus intérpretes contemporáneos. Quizás sea Hans-Georg Gadamer el caso más paradigmático de esta situación ${ }^{12}$, de ahí su nefasta, aunque decisiva influencia en la recepción e interpretación contemporánea de la fenomenología, en general, y de Husserl en particular, a propósito de su reivindicado giro hermenéutico de la fenomenología ${ }^{13}$.

Los Seminarios de Zollikon resultan un fiel reflejo de esta ambigua relación entre Heidegger y la fenomenología de Husserl: por un lado, Heidegger reivindica la fenomenología y el "pensar fenomenológico» (2013, 107), así como el método fenomenológico $(2013,179)$, enfatizando que «debemos comprender adecuadamente lo característico de la fenomenología y cuidarnos de malinterpretarla como una entre otras "direcciones y escuelas de la filosofía» $(2013,210)$. Pero a partir de estas indicaciones negativas, que indican lo que no es la fenomenología, difícilmente podremos comprender lo que ésta sea sustancialmente. Por otro lado, junto a esta reivindicación de la fenomenología, encontramos una crítica y un distanciamiento expreso de Husserl, el cual habría fijado "las determinaciones del ser humano como subjetividad y como conciencia de un yo trascendental» $(2013,193)$; quien, en definitiva, se hallaría preso aún, con

12. Cfr. GAdAMER, H-G.: El movimiento fenomenológico, Síntesis. Madrid, 2016. Especialmente significativo resulta el artículo "Fenomenología, hermenéutica, metafísica", pp. 149-162. Compare el lector las ideas que Gadamer expone allí sobre Husserl con las que defendemos en este trabajo y se comprenderá el porqué de mi afirmación respecto al desconocimiento de la fenomenología de Husserl por parte de Gadamer.

13. No podemos ocuparnos aquí de esta problemática, pero baste señalar que quizás -o con seguridad, en mi opinión- debiera ser cuestionado el generalmente asumido giro hermenéutico de la fenomenología proclamado y encabezado por Gadamer, para cuestionarnos qué significa y qué implica este giro hermenéutico. Suele entenderse que este giro o transformación hermenéutica de la fenomenología supone una "superación" de la misma en tanto que la hermenéutica no puede asumir ni el "idealismo" de Husserl ni su planteamiento "trascendental", puesto que la historicidad radical de la que parte la hermenéutica no deja ya lugar para tales planteamientos. He aquí el punto que, según me parece, debe ser repensado, puesto que en él encontramos la discrepancia decisiva entre la fenomenología de Husserl -defensor de una racionalidad fuerte- y la hermenéutica de Gadamer, así como la distancia con otros pensadores de la llamada "PostModernidad", tales como Vattimo, Deleuze, Foucault, Badiou, etc. En síntesis cabría señalar que la fenomenología de Husserl es ya hermenéutica, puesto que parte de la "actitud natural" inicial del fenomenólogo -siempre concreta, histórica y cultural-, pero no se detiene en esta posición o perspectiva relativista-historicista, sino que pretende superarla mediante el método de la epojéreducción, para lograr el ámbito trascendental propio del ser humano. Por ello defendemos que Heidegger, frente a los citados autores, es un fenomenólogo en estricto sentido husserliano, puesto que asume y practica el método husserliano de la epojé-reducción, cuya finalidad, insistimos, no es otra que reconducirnos al carácter trascendental del ser humano y, desde ahí, repensar su realidad. Por tanto, no rechazamos la hermenéutica gadameriana como tal, sino el giro hermenéutico de la fenomenología en el sentido expuesto por Gadamer, pues ello supondría renunciar a las convicciones fundamentales de la fenomenología. 
Descartes, del esquema moderno sujeto-objeto (cfr. 2013, 223 y ss.) y, por ello, anclado en un planteamiento análogo al cientificista que Heidegger critica en estos Seminarios.

Ante esta ambigua relación, nuestra tarea no será otra que poner en claro qué es la fenomenología, qué pretende y qué nociones fundamentales articulan su método. La tesis que defenderemos aquí es que la fenomenología reivindicada por Heidegger no es otra que la fenomenología de Husserl, de ahí que debamos distinguir la postura explícita de Heidegger frente a su posición implícita en relación con la fenomenología de Husserl. No entraremos aquí en disputas psicológicas -si Heidegger conocía o no los textos de Husserl, y si los conocía, qué motivaciones personales tenía para comportarse así con su maestro. Tampoco entraremos en disquisiciones historiográficas -quién es más original o quién influyó más en quién, etc. Ni siquiera entraremos a considerar explícitamente la validez de las críticas de Heidegger contra Husserl, pues, según me parece, ésta quedará puesta en entredicho en cuanto nos acerquemos a la fenomenología del maestro.

Para abordar esta tarea debemos alejarnos del «Husserl convencional», cuyos tres rasgos fundamentales serían los siguientes: «la epojé como búsqueda de apodicticidad, el sujeto trascendental como único y abstracto, y la reducción trascendental como necesariamente eidética» (San Martín, 2015, 53). Esta imagen caricaturesca de la fenomenología de Husserl es la que ha sido instaurada y generalmente asumida por gran parte de los intérpretes de Heidegger, con lo cual queda desactivado el verdadero alcance y significación que la fenomenología juega en éste último más allá de etiquetas formales y vacías. Por tanto, más allá de las declaraciones explícitas de Heidegger contra Husserl, nos remitimos ahora a los textos mismos, pues sólo éstos pueden ofrecernos una auténtica respuesta a la cuestión que nos ocupa: ¿en qué consiste la fenomenología y el método fenomenológico que Heidegger reivindica?

Como es sabido, la fenomenología nace con la publicación de las Investigaciones lógicas (1900) de Edmund Husserl, cuyo objetivo no es otro que ofrecer una respuesta contundente al psicologismo y cientificismo imperante en el siglo XIX y principios del XX. La cuestión es clara: si la verdad, la razón y la ciencia son meras cuestiones de hechos contingentes -Positivismo- o se fundamentan en nuestra configuración psicológica Psicologismo-, la crisis no es sólo teórica, sino práctica: lo que está amenazada es la razón práctica (ética-política), y con ella la realidad humana en cuanto tal. Lo que está en juego, en definitiva, son dos visiones enfrentadas del ser humano: la cientificista y la filosóficafenomenológica. La primera reduce al ser humano a un hecho físico-fisiológico más; la segunda reconduce la realidad humana a su rasgo más fundamental, a su «carácter de abierto para lo presente», en palabras de Heidegger $(2013,127)$. Esta reducción o reconducción fenomenológica del ser humano a sus rasgos fundamentales sólo se puede 
lograr mediante la puesta entre paréntesis -epojé- de la comprensión natural que tenemos del ser humano y, en el caso que nos ocupa, de las ciencias naturales -actitud naturalista-, de ahí que Heidegger comience los Seminarios advirtiendo que "para lo que se va a discutir ahora, se tiene que neutralizar (ausgeschaltet) ${ }^{14}$ toda ciencia por el momento; es decir, no se debe hacer uso ahora de ella» $(2013,37)$. Por tanto, en consonancia con Husserl, la epojé no es aquí una búsqueda de apodicticidad, de certeza absoluta, sino, tal y como se expone en las lecciones Problemas fundamentales de la fenomenología (1910), la epojé instaura ante todo una "una actitud completamente diferente de la actitud natural», y es necesario aclarar desde el comienzo qué significa esto para Husserl:

La fenomenología no es, de ningún modo, psicología, pues se emplaza en una dimensión nueva y reclama una actitud esencialmente diferente de la que es propia de la psicología y de la de cualquier ciencia de lo espaciotemporalmente existente ${ }^{15}$.

La epojé instaura, pues, una nueva actitud con el fin de «poner entre paréntesis» los prejuicios y preconcepciones establecidas respecto al objeto, ámbito o tema a investigar. Esta misma noción de epojé es la que tiene en mente Heidegger cuando advierte a los psiquiatras: "Como médicos formados científicamente están ustedes en gran parte determinados por el modo de pensar de las ciencias naturales» $(2013,106)$. La alternativa

14. Es necesario insistir en la importancia del término empleado por Heidegger, "ausgeschaltet", que Ángel Xolocotzi traduce como "neutralizar". El texto de Heidegger es el siguiente: "Für das, was jetzt besprochen werden soll, muß einmal alle Wissenschaft ausgeschaltet werden; $d$. $h$. es soll von ihr jetzt nicht Gebrauch gemacht werden". En ningún momento se hace alusión alguna a la epojé husserliana, a pesar de que ésta es presentada por Husserl, precisamente, con el mismo término, "Ausschaltung", traducido al castellano, generalmente, como "desconexión". El siguiente texto de Husserl, de 1910, nos muestra hasta qué punto Heidegger asume y hace tanto la epojé como la distinctio phaenomenologica husserliana: "Wir können jede natürliche Setzung (Setzung von Naturdasein) in dem Sinn ausschalten, dass wir wissenschaftliche Betrachtungen anstellen, in denen wir schlechtin von keiner Setzung von Natur Gebrauch machen und die somit Geltung behalten, ob es eine Natur, eine geistig-leibliche Welt überhaupt gibt oder nicht" (Hua XIII, p. 144) [las negritas son mías]. Aquí nos presenta Husserl un aspecto esencial de la epojé o «desconexión» de la "posición natural», en tanto que "no hagamos uso de ninguna posición de la Naturaleza», resultando esta "desconexión" una condición necesaria o paso previo para o hacia la reducción trascendental. Este primer sentido -negativo o privativo- de la epojé como "desconexión" será superado o reintegrado posteriormente en la práctica de la reducción trascendental -momento positivo de la epojé (en tanto que posibilitadora de la práctica fenomenológica). Por tanto, no sería erróneo traducir "ausschalten" por "neutralizar" -como hace Xolocotzi-, siempre que no perdamos de vista el sentido en que lo emplean tanto Husserl como Heidegger, que no es otro que como práctica de la epojé fenomenológica.

15. HUSSERL, E.: Problemas fundamentales de la fenomenología, Alianza, Madrid, 1973. Traducción de J. San Martín y C. Moreno, p. 47. 
a ese modo de pensar no es otro que el "pensar fenomenológico» $(2013,107)$, cuyo propósito es «hacer visible cada fenómeno propiamente en su peculiaridad» $(2013,114)$.

La fenomenología no niega pues la validez ni de la ciencia ni de su método -lo cual sería absurdo-, sino sólo su «absolutización», de ahí que, como se ha indicado, la función del método fenomenológico sea ofrecer una alternativa a la visión cientificista del ser humano, ya que, para Heidegger, "la ciencia natural sólo puede constatar al ser humano como algo que está simplemente ahí en la naturaleza» $(2013,57)$. Esta motivación éticopráctica inherente a la fenomenología no puede ser obviada, puesto que en ella se juega su sentido y su motivación. Una prueba irrecusable de esta profunda motivación éticopráctica la ofrecen los artículos escritos por Husserl a comienzos de los años veinte, en pleno derrumbe de la cultura europea, asolada por la Primera Guerra mundial, cuyo significativo título reza Renovación del hombre y de la cultura ${ }^{16}$. Esta misma preocupación ético-práctica queda recogida en la pregunta por el ser del ser humano o Dasein en Ser y tiempo, de ahí que Pedro Cerezo haya insistido en la "profunda inspiración ética a que responde esta obra» (Cerezo, 1991, 14). Desde esta perspectiva ético-práctica, la epojé o neutralización fenomenológica de la ciencia y la actitud natural soló cobra sentido enfocada hacia la reducción o reconducción trascendental del ser humano a sus rasgos fundamentales, y así lo entiende también Heidegger cuando afirma en Ser y tiempo lo siguiente:

El ser es lo transcendens pura y simplemente. La trascendencia del ser del "ser ahí" es una señalada trascendencia, en cuanto que implica la posibilidad y la necesidad de la más radical individuación. Todo abrir el ser en cuanto transcendens es conocimiento trascendental. La verdad fenomenológica (el "estado de abierto del ser") es veritas trascendentalis ${ }^{17}$.

16. HUSSERL, E.: Renovación del hombre y de la cultura. Cinco ensayos, Anthropos, Madrid, 2012. Traducción de A. Serrano de Haro.

17. HEIDEGGER, M.: El ser y tiempo, ed. cit., p. 49. La dependencia del ser respecto al ser humano -o Dasein-queda expresamente señalada al comienzo de Conceptosfundamentales de la fenomenología, donde Heidegger afirma: "el análisis del carácter de verdad del ser muestra precisamente que también el ser asimismo se funda en un ente, a saber, el Dasein. Sólo hay ser si hay comprensión del ser, esto es, si existe el Dasein. (...). La ontología tiene como disciplina fundamental la analítica del Dasein. En ello se funda asimismo el hecho de que la ontología no pueda fundamentarse de una forma puramente ontológica. Su posibilidad misma remite a un ente, esto es, a lo óntico: al Dasein. La ontología tiene un fundamento óntico» (Op. cit., p. 45). En otras palabras, que no suelen satisfacer a los intérpretes de Heidegger: la ontología remite a la antropología filosófica -o analítica del Dasein. Sólo que ésta última se realiza una vez practicada la reducción fenomenológica trascendental, de ahí que la descripción fenomenológica de los existenciarios que Heidegger lleva a cabo en Ser y tiempo no pueda ser concebida en términos de las ciencias particulares -antropología, biología, etc., sino como antropología fenomenológica trascendental o, en palabras de Heidegger, como analítica 
En mi opinión, gran parte de las críticas lanzadas contra la «subjetividad trascendental» de Husserl -también las del propio Heidegger-, pierden su sentido y validez cuando se comprende que la noción de «trascendental» en Husserl no implica «idealismo moderno» alguno, que no se trata de "filosofía de la conciencia» ni "psicologismo», sino que con esta noción Husserl no hace sino constatar, al igual que Heidegger, que sin subjetividad trascendental o Dasein no hay ser: "Sólo hay ser si hay comprensión del ser, esto es, si existe el Dasein ${ }^{18}$. Ningún intérprete de Heidegger -hasta donde yo conozco- ha visto en estas palabras indicios de idealismo, psicologismo o subjetivismo, pues, ciertamente, ¿cómo puede hacer «ser» sin "ser humano»? Podría haberlo, pero entraríamos en el ámbito de la teología, y no ya de la filosofía: en cualquier caso, hablaríamos de una realidad sin ser humano o que prescinde de él, lo cual es difícilmente pensable -al menos para nosotros.

Por esta razón la realidad es fenomenológica, y ésta presupone siempre una subjetividad trascendental o Dasein a quien «se dan» los fenómenos. Por ello hablamos en fenomenología de "constitución trascendental», para enfatizar que la subjetividad trascendental o Dasein no es un mero hecho mundano más, sino, al contrario, la condición de posibilidad de todo hecho. Esto quiere decir para Husserl que la subjetividad trascendental es una "realidad absoluta», de ahí que -afirma Husserl- "Hablando en absoluto, sólo existe el ego y su vida, y ésta está «vinculada» con el otro ego en su vida»" A los lectores de Ortega y Gasset resonarán estas palabras de Husserl a la idea orteguiana de "mi vida» como "realidad radical» expuesta ampliamente en ¿Qué es filosofía? $(1929)^{20}$, pues, ciertamente, a ello apunta «/a vida radical como conciencia trascendental» (San Martín, 2013). Esta noción de absoluto en relación con la subjetividad trascendental no presenta ya sólo, ni principalmente, un carácter epistemológico, sino plenamente ontológico, en tanto que ésta se nos muestra como des-ligada o no-dependiente de hecho fáctico alguno. Heidegger, en línea con la fenomenología de Husserl, nos remite al "carácter de abierto para lo presente» $(2013,127)$ propio del Dasein, condición de posibilidad de todo lo "presente» (Vorhandensein). Pero que éste "constituye» la

del Dasein. Pero ésta, debe insistirse, sólo es posible gracias a la práctica de la epojé-reducción fenomenológica, pues sólo por ella ponemos en cuestión lo que Heidegger denomina "comprensión de término" del ser y lograr, así, la mirada fenomenológica trascendental.

18. HEIDEGGER, M.: Op. cit., p. 45

19. HUSSERL, E.: Problemas fundamentales de la fenomenología, ed. cit., p. 201.

20. ORTEGA Y GASSET, J.: ¿Qué es filosofía? (1929), en: Obras completas, Tomo VII, Madrid, Alianza Editorial/ Revista de Occidente, 1983, p. 99 y ss. 
realidad no significa que la crea, inventa o representa (ni psicológica ni físicamente), sino, sencillamente, como venimos mostrando, que el ser nunca existe sin el ente ${ }^{21}$.

Hasta aquí hemos mostrado cómo dos nociones fundamentales de la fenomenología de Husserl y el método fenomenológico -la «epojé» y la «reducción trascendental»-son asumidas por Heidegger y subyacen implícitamente a sus planteamientos filosóficos. Con ello nos hemos desprendido de dos rasgos característicos del que hemos denominado "Husserl convencional», mostrando la auténtica significación de ambas nociones en la fenomenología. Sin embargo, resta aún lo más importante: mostrar cómo la subjetividad trascendental de la fenomenología de Husserl es un «cuerpo vivido» (Leib) y qué consecuencias se desprenden de ello. Nos proponemos entonces desmontar el tercer rasgo del "Husserl convencional», según el cual éste comprendería al "sujeto trascendental como único y abstracto» (San Martín, Ibíd.). Así es, efectivamente, como Heidegger nos presenta a su maestro, llegando a afirmar que la fenomenología de Husserl «sigue siendo fenomenología de la conciencia, impide una visión clara en la hermenéutica fenomenológica del Dasein» (2013, 193-194), de ahí la insistente crítica de Heidegger: «Hasta y con Husserl le llama uno a esto el idealismo moderno» $(2013,229)$.

Sin embargo, esta interpretación de la fenomenología de Husserl resulta ya insostenible dadas las publicaciones y evidencias textuales de lo que se ha dado en llamar «The new Husserl» ${ }^{22}$. Ciertamente, como nos muestra San Martín en sus trabajos, y más recientemente en La nueva imagen de Husserl (2015) ${ }^{23}$, este Husserl que reivindicamos no tiene nada de «new», sino que siempre había estado ahí -si bien ignorado o desconocido. No es la fenomenología de Husserl un «idealismo moderno» como afirma Heidegger, sino que, por el contrario, desde muy temprano concibió Husserl la subjetividad trascendental como «cuerpo vivido» (Leib), noción apuntada ya en 1910 en las citadas lecciones Problemas fundamentales de la fenomenología. Sin embargo, en ellas no emplea Husserl todavía el término «cuerpo» (Körper) para referirse al ser humano como mero «cuerpo físico», -frente al "cuerpo vivido» (Leib)-, sino que el ser humano es entendido en estas lecciones, en general, como «viviente» (Leiber). Esta importante distinción referida al ser humano como «cuerpo» (Körper) y «cuerpo vivido» (Leib) no la desarrolla Husserl hasta

21. Jean Grondin comenta esta problemática y las paradojas "inauditas" que, en su opinión, supone este planteamiento trascendental de Ser y tiempo. Cfr. RODRíGUEZ, R. (coord.): Ser y tiempo de Heidegger. Un comentario fenomenológico, Trottta, Madrid, 2015, p. 20, nota 7 y p. 27 y ss.

22. Welton, D. (2003): The new Husserl. A Critical Reader, Indiana University Press.

23. Me permito remitir al lector interesado a la reseña que realizo de esta obra en Daimon. Revista Internacional de Filosofía, no 68, 2016, pp. 180-183. 
Ideas II, donde la subjetividad trascendental es presentada ya como «persona» ${ }^{24}$, y así la reconoce Husserl como sustrato de convicciones, opiniones, habitualidades, decisiones, evaluaciones, recuerdos, etc. ${ }^{25}$ La subjetividad trascendental -histórica, personal y concreta- es lo que descubre la reducción trascendental, y no sólo un ámbito eidético puro de la conciencia, como se suele insistir para criticar a Husserl.

Esta distinción clave la pone Heidegger en relación con la problemática del método, llegando a afirmar que "el problema del cuerpo (Leib) es un problema de método» (2013, 179). Esta importante afirmación queda totalmente justificada, según el planteamiento de Heidegger, si la situamos en el contexto de los Seminarios, cuyo trasfondo no apunta sólo a un diálogo crítico con la psiquiatría y la psicología, sino, más ampliamente, con las ciencias naturales y su método, en tanto que Heidegger retrotrae la discusión a la pregunta por los fundamentos ontológicos de éstas. Estos fundamentos serían, según Heidegger, los que pasarían desapercibidos al científico de las ciencias naturales, puesto que los asumiría como presupuestos válidos de suyo, de ahí que Heidegger insista en mostrar cómo también "la física está fundada en una ontología tácita» $(2013,197)$. En tales ciencias -arguye Heidegger- rige el principio de la «causalidad» (Kausalität), que es ya «una determinación ontológica», mientras que la «motivación concierne a la existencia del ser humano en el mundo en tanto ente que actúa y tiene experiencias» $(2013,54)$. Para Heidegger, se trata, en definitiva, de mostrar que «la pregunta de qué, quién y cómo es el ser humano -y esto quiere decir, al mismo tiempo, el ser humano actual- es de una importancia fundamental», y "esta pregunta en cuanto al contenido» no deja de ser "a la vez una pregunta en cuanto al método» $(2013,106)$. Advertimos aquí hasta qué punto es crucial la problemática del método, puesto que ésta será la que oriente nuestra comprensión o determinación de qué sea el "ser humano», y con ello, tanto nuestro ámbito de investigación como las respuestas que se ofrezcan a los problemas suscitados. Desde esta perspectiva, podrá afirmar Heidegger que exigir que «la relación entre soma y psique sea mensurable» supone "una exigencia injustificada, ya que no proviene del estado de cosas en cuestión, sino de una exigencia y un dogma científico-naturales: sólo es real aquello que es mensurable» $(2013,138)$. Con ello tocamos un tema clave -la relación entre soma y psique-, transfigurado ahora por Heidegger desde la «mirada fenomenológica».

Pero, ¿ por qué resulta tan importante la fenomenología en esta cuestión? La respuesta la obtenemos cuando caemos en la cuenta $-y$ esto es decisivo aquí- de que toda la

24. HUSSERL, E.: Ideas relativas a una fenomenología pura y una filosofía fenomenológica. Libro Segundo: Investigaciones fenomenológicas sobre la constitución, ed. cit., p. 301.

25. Ibídem, cfr. §29, p. 148 y ss. 
argumentación heideggeriana remite, en última instancia, a una distinción fundamental en la fenomenología de Husserl, y no es otra que la «distinctio phaenomenologica» que Husserl expone en las lecciones de 1910, la cual establece que, "por así decirlo, podemos cortar sin contrasentido el vínculo empírico entre vivencia y toda existencia cósica. Ejecutamos una cierta distinctio phaenomenologica ${ }^{26}$. Es justamente esta posibilidad la que abre la puerta a todos los análisis anteriores, y a ella remite también la distinción misma entre «cuerpo cósico» (K) y «cuerpo vivido» (L). En un manuscrito inédito -el BII 19 , de $1912^{27}$ - explica Husserl la importancia de la distinctio phaenomenologica, puesto que en ella se juega la posibilidad misma de la fenomenología como «investigación de la realidad» (Realitätsforschung), como «dominio de ciencias» (Domäne von Wissenschaften) que no se reducen "a lo material» (auf Materielles), sino que, además, se constituyen independientemente y sin una relación necesaria con «lo materia/» ${ }^{28}$. Desde esta distinctio phaenomenologica diferencia Husserl al ser humano como "cuerpo» (Körper) meramente «extendido» (extendiert) en el espacio frente al «cuerpo viviente» (Geister), que no se encuentra sólo «extendido», sino «localizado» (lokalisiert), resultando que "esta localización es algo fundamentalmente distinto de la extensión» («Diese Lokalisation ist etwas Grundverschiedenes von der Extension ॥, B II 19, 10b). Como venimos mostrando, esta distinctio phaenomenologica y las descripciones fenomenológicas que ella posibilita jugarán un papel central en los Seminarios de Zollikon de Heidegger. Así lo entiende también Heidegger cuando afirma lo siguiente:

Este "estar en medio de» tiene generalmente el carácter del percibir corporal (L) cosas que están ahí en persona. Pero nuestro estar-aquí también puede insertarse en el estar en medio de lo no presente en persona. Si no existiese esta posibilidad y no fuese ejecutada, entonces, por ejemplo, ustedes nunca llegarían a casa esta noche $(2013,126)$.

26. HUSSERL, E.: Problemas fundamentales de la fenomenología, ed. cit., p. 78.

27. Gracias a la sugerencia de mi director de tesis, Javier San Martín, quien sabía de la importancia de este manuscrito inédito de Husserl para el tema que nos ocupa, tuve la oportunidad de consultar este texto durante una breve estancia de investigación en el Archivo Husserl de Friburgo (enero de 2016). Igualmente he de agradecer la amabilidad del director del Archivo Husserl de Lovaina, el profesor Ulrich Melle, por su autorización para emplear y publicar algunos fragmentos del citado manuscrito BII 19

28. En consonancia con las lecciones de 1910, en el manuscrito de 1912 explica Husserl, a raíz de la distinctio phaenomenologica, que el "mundo» del que se ocupa la investigación fenomenológica no es sólo el cósico o material de las ciencias naturales, sino que -escribe Husserl- «el mundo, esto es un título para el todo de realidades de más bajo y más alto grado» ("Die Welt, das ist ein Titel für das All der Realitäten niederer und höherer Stufe», B II 19, 14a). 
Es justamente esta posibilidad descubierta por el método fenomenológico lo que Husserl denomina distinctio phaenomenologica, piedra angular de toda la fenomenología, mientras que Heidegger, en analogía con lo anterior, «divisa la diferencia ontológica; esto es, la diferencia entre ser y ente, donde el primero es accesible en forma diferente al ente» $(2013,65)$. Sin embargo, no debemos olvidar que todas estas conclusiones sólo han sido posibles gracias a la práctica del método fenomenológico, de modo que, insistimos, supondría un gravísimo error pensar que no hay método alguno en la filosofía de Heidegger o que, si lo hay, su papel sería meramente formal o secundario. A mi juicio, las interpretaciones que minusvaloran el papel de la fenomenología de Husserl y su método en los textos heideggerianos -sea por desconocimiento de aquélla, sea por la interpretación que Heidegger impone de su maestro-impiden comprender la profundidad y el potencial de los conceptos y planteamientos fenomenológicos que hay en juego. En un plano exclusivamente teórico, académico o historiográfico, la incomprensión de la fenomenología no supondría mayores inconvenientes para el investigador, pero cuando pretendemos ampliar el horizonte y ofrecer desde la filosofía una respuesta fuerte y contundente a una determinada visión reduccionista del ser humano -a las neurociencias actuales, por ejemplo-, entonces lo que está en juego, dice Heidegger, no es ya una mera cuestión teórica, sino «la destrucción del ser humano» $(2013,197)$. He aquí el motivo de nuestra insistente reivindicación de la fenomenología como filosofía práctica, tanto de Heidegger como de Husserl que, en definitiva, vienen a coincidir en lo fundamental.

\section{Bibliografía}

CEREzo, P. "De la existencia ética a la ética originaria", en: Duque, F. (ed.), Heidegger o la voz de los tiempos sombríos, Serbal, Barcelona, 1991, pp. 11-79.

GADAMER, H-G: El movimiento fenomenológico, Síntesis, Madrid, 2016.

HEIDEgGeR, M.: Conceptos fundamentales de la fenomenología, Trotta, Madrid, 2000. Traducción de J. J. García Norro.

HEIDEGGER, M.: El ser y el tiempo, FCE, México, 2007. Traducción de J. Gaos.

HeIDEgGeR, M.: Prolegómenos para una historia del concepto de tiempo, Alianza, Madrid, 2006. Traducción de J. Aspiunza Elguezabal.

HeIDegGeR, M.: Seminarios de Zollikon, Herder, México, 2013. Traducción de Á. Xolocotzi Yánez.

HUSSERL, E.: Problemas fundamentales de la fenomenología, Alianza, Madrid, 1973. 
Traducción de J. San Martín y C. Moreno.

HUSSERL, E.: Ideas relativas a una fenomenología pura y una filosofía fenomenológica. Libro Segundo: Investigaciones fenomenológicas sobre la constitución, FCE, México, 1997. Traducción de A. Zirión.

HUSSERL, E.: Renovación del hombre y de la cultura. Cinco ensayos, Anthropos, Madrid, 2012. Traducción de A. Serrano de Haro.

HUSSERL, E.: Manuscrito B I/ 19 (Aus Vorlesung 1912 über Reduktion), inédito.

NIETZSCHE, F.: La voluntad de poder, EDAF, Madrid, 1981, p. 240. Traducción de Aníbal Froufe.

ORTEGA Y GASSET, J: ¿Qué es filosofía? (1929), en: Obras completas, Tomo VII, Madrid, Alianza Editorial/ Revista de Occidente, 1983.

RODRígUEZ, R. (coord.): Ser y tiempo de Heidegger. Un comentario fenomenológico, Trottta, Madrid, 2015.

ROdRígueZ, R.: Heidegger y la crisis de la Época moderna, Síntesis, Madrid, 1994.

SAN MARTIN, J.: La estructura del método fenomenológico, UNED, Madrid, 1986.

SAN MARTIN, J.: La nueva imagen de Husserl. Lecciones de Guanajuato, Trotta, Madrid, 2015.

SAN MARTIN, J.: "La vida radical como conciencia trascendental", en Revista de Humanidades 28, Universidad Andrés Bello, julio-diciembre 2013, Santiago de Chile, pp. 229-247.

WELTON, D.: The new Husserl. A Critical Reader, Indiana University Press, 2003. 